\title{
Diseminasi Teknologi Mesin Perajang Tembakau dalam Upaya Menerapkan Ekoteknologi di Desa Tumbrasanom Kecamatan Kedungadem Kabupaten Bojonegoro
}

\author{
Mega Novita ${ }^{1}$, Muhdi $^{1}$, Achmad Buchori $^{1}$, Ali Mujahidin ${ }^{2}$ \\ ${ }^{1}$ Universitas PGRI Semarang, ${ }^{2}$ IKIP PGRI Bojonegoro \\ sigit.ristanto@gmail.com
}

Submitted: 12 December 2018. Revised: 3 March 2019. Accepted: 27 July 2019

Key word:

Dissemination, ecotechnology, automatic tobacco chopper tools

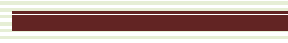

\section{Kata Kunci}

Diseminasi, ekoteknologi, alat perajang tembakau otomatis

\section{Abstract}

The villagers of Tumbrasanom have 4 business groups, namely prosperous farmers, totaling 40 people, who do not have automatic tobacco chopper tools. In the manufacture and marketing of tobacco chopper products in the village of Tumbrasanom it is still simple. Then the marketing of its products has not been done online and there is no partner network, therefore it needs to be given a touch of appropriate technology that is environmentally friendly by using automatic tobacco chopper. The activity of disseminating technology products to the public aims to improve the welfare of citizens through increasing tobacco production capacity with automatic tobacco chopper tools using ecotechnology strategies, as well as increasing the value of sales and marketing. Outputs that have been generated from this activity include the development of a number of group members, training in the use and maintenance of automatic tobacco chopping tools, training in the use of automatic tobacco chopper tools, training in tobacco processing and good financial management training and sales and marketing of tobacco products and chopper machines automatic tobacco. The automatic tobacco chopper tool produced is 8 pieces with a capacity of $5 \mathrm{~kg} /$ minute.

\section{Abstrak}

Warga Desa tumbrasanom mempunyai kelompok usaha yaitu tani makmur sebanyak 4 kelompok yang berjumlah 40 orang, yang belum memiliki alat perajang tembakau otomatis. Pembuatan dan pemasaran produk alat perajang tembakau di desa tumbrasanom ini masih sederhana dan belum adanya jejaring mitra, oleh karena itu perlu diberikan sentuhan teknologi tepat guna yang ramah lingkungan dengan menggunakan alat perajang tembakau otomatis. Kegiatan diseminasi produk teknologi ke masyarakat ini bertujuan untuk meningkatkan kesejahteraan warga melalui peningkatan kapasitas produksi tembakau dengan alat perajang tembakau otomatis dengan menggunakan strategi ekoteknologi, serta peningkatan nilai penjualan dan pemasarannya. Luaran yang telah dihasilkan dari kegiatan ini antara lain 1) penambahan jumlah anggota kelompok; 2) kelompok memahami cara menggunakan dan merawat mesin perajang; 3) melakukan pemasaran online. 


\section{PENDAHULUAN}

Kelurahan Tumbrasanom terletak di Kecamatan Kedungadem Kabupaten Bojonegoro, yang luas wilayahnya 376.69 Ha, yang terdiri dari tanah sawah $31.89 \mathrm{Ha}$, tanah kering $225.3 \mathrm{Ha}$, tanah fasilitas umum 117.5 Ha, dan tanah hutan $2 \mathrm{Ha}$ Wilayah Kelurahan Tumbrasanom terbagi atas 4 dusun, 16 Kadus dan 13 Rw, dan nama dusun-dusunnya antara lain; Dusun Tumbras, Dusun Gempol dan Dusun Ringin Anom. Desa Tumbrasanom merupakan wilayah pengembangan perkotaan Kecamatan Kedungadem, hal ini menunjukkan posisi bahwa desa memiliki lokasi yang cukup strategis karena berada pada jalur tengah jalan propinsi jawa timur dan dekat Pantura.

Berdasarkan Sumber data Statistik Desa Tumbrasanom, Kedungadem Bojonegoro tahun 2017 dalam hal pendidikan diketahui anak yang sekolah TK/sederajat sebanyak 182 orang, Tamat SD/sederajat sebanyak 229 orang, Tamat SMP/ sederajat sebanyak 1270 orang, Tamat SMA sebanyak 856 orang dan Perguruan Tinggi sebanyak 238 orang, hal ini menunjukkan bahwa potensi Sumber daya manusia Desa Tumbrasanom cukup memadai dengan banyaknya warga yang berpendidikan sarjana.
Menurut data statistika yang dikeluarkan oleh Direktorat Jenderal Perkebunan, Kabupaten Bojonegoro adalah penghasil Tembakau Virginia terbesar di Jawa Timur (Perkebunan D.J, 2016). Luas area perkebunan tembakau di Bojonegoro tersebar di beberapa wilayah. Kecamatan Kedungadem merupakan kawasan penghasil Tembakau terbesar ketiga di Bojonegor .

Hasil observasi di Desa Tumbrasanom, menunjukkan beberapa data berikut: jumlah anggota kelompok usaha pengolah tembakau yang masih sedikit, proses pembuatan alat perajang tembakau masih sederhana masih memakai alat pertukangan manual, belum menggunakan mesin/ teknologi modern, belum adanya tempat display produk alat perajang tembakau yang menarik, belum adanya pelatihan yang spesifik berkaitan alat perajang tembakau dengan mesin terbarukan.

Keberadaan mesin tradisional dengan alat sederhana menjadikan load kapasitas dalam perajangan tembakau juga terbatas. Tingkat efisiensi mesin yang tinggi dapat mempercepat pemenuhan kebutuhan tembakau yang sudah dirajang. Hal ini sama dengan efisiensi mesin perajang rumput yang meningkatkan 
kecepatan pemenuhan kebutuhan rumput

(Sugandi, Yusuf, \& Saukat, 2016).

Kelompok dan kemitraan dalam pertanian sangat penting dalam pengembangan agribisnis tembakau dan meningkatkan daya saing (Nur \& Salim, 2018). Berdasarkan analisis kondisi ini, tim pengabdi memilih Desa Tumbrasanom Kecamatan Kedungdalem sebagai lokasi untuk Diseminasi Mesin Perajang Tembakau yang telah dibuat oleh Universitas PGRI Semarang yang dalam desainnya mempertimbangkan mobilitas dan kemudahan pengoperasian.

\section{METODE}

Pihak yang menjadi mitra dalam kegiatan diseminasi teknologi ini adalah Kelompok tani Makmur 1 dan kelompok Tani Makmur 3. Kedua kelompok ini dikoornatori oleh ketua dan beberapa orang pengurus. Kelompok ini beranggotakan 20 orang yang mayoritas adalah bapak-bapak dan ibu-ibu rumah tangga dan remaja yang tidak bekerja. Pelaksanaan pengabdian kepada kedua kelompok ini melibatkan IKIP Bojonegoro dalam hal pelatihan manajemen. Tahapan dalam Penerapan Teknologi kepada Masyarakat ditunjukkan pada Tabel 1.

Tabel 1. Metode Pelaksanaan Pengabdian

\begin{tabular}{lll}
\hline No & Jenis Kegiatan & Metode \\
\hline 1 & Identifikasi Kebutuhan Masyarakat & Wawancara dan Observasi Langsung \\
2 & Perancangan & Diskusi \\
3 & Pembuatan & Sosialisasi, praktek dan diskusi \\
4 & Uji Operasi & Pengamatan \\
5 & Pendampingan Operasional & Diskusi, praktek dan tanya jawab \\
6 & Diseminasi teknologi tersebut kepada & Diskusi, praktek dan tanya jawab \\
& masyarakat/mitra & \\
\hline
\end{tabular}

HASIL

Kegiatan yang telah dilakukan dalam program Diseminasi Teknologi Mesin Perajang Tembakau bagi Masyarakat Desa Tumbrasanom Kecamatan Kedungadem Kabupaten Bojonegoro adalah sebagai berikut:

1. Sosialisasi program kegiatan Diseminasi Mesin Perajang Tembakau
Informasi tentang kebutuhan warga desa wukirsari didapatkan dari pemetaan analisis kebutuhan warga saat musim tanam tembakau bulan Juni s.d September 2018, hasil diskusi dengan berbagai tokoh masyarakat diperoleh data bahwa $70 \%$ masyarakat masih menggunakan mesin perajang tembakau tenaga listrik dan mayoritas warga belum menggunakan mesin 
perajang tembakau tenaga diesel yang bisa mobile dibawa kemana saja di sawah, selama ini warga kesulitan mencari mesin perajang tembakau tenaga diesel. Penggunaan Mesin perajang tembakau dapat berdampak besar pada kapasitas produksi Pemilihan elemen alat dan mesin juga perlu diperhatikan untuk tujuan efisiensi (Sugandi dkk., 2016). Penerapan mesin selama revolusi industri juga telah terbukti meningkatkan produktivitas, sehingga pembaruan mesin perajang diharapkan dapat meningkatkan produktivitas (Amelia, Iqbal, \& Useng, 2018). Proses survey lokasi petani tembakau di Desa Tumbrasanom ditunjukkan pada gambar 1 .

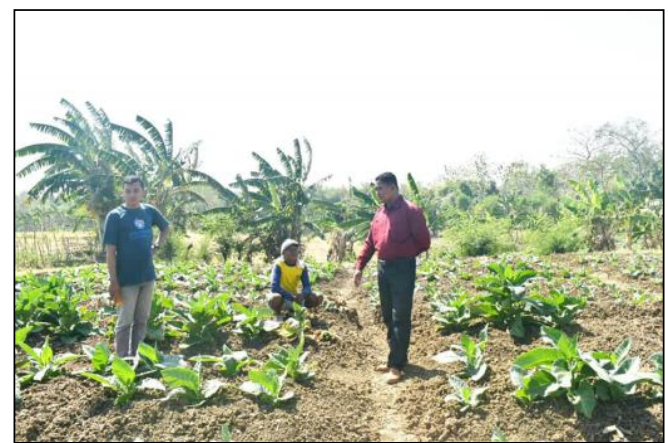

Gambar 1. Survey lokasi petani tembakau di Desa Tumbrasanom

Desain mesin perajang tembakau otomatis ditunjukkan pada gambar 2 . Mesin ini memiliki spesifikasi teknis mampu merajang tembakau 5 kg/menit. Daya listrik yang dibutuhkan 100 Watt.

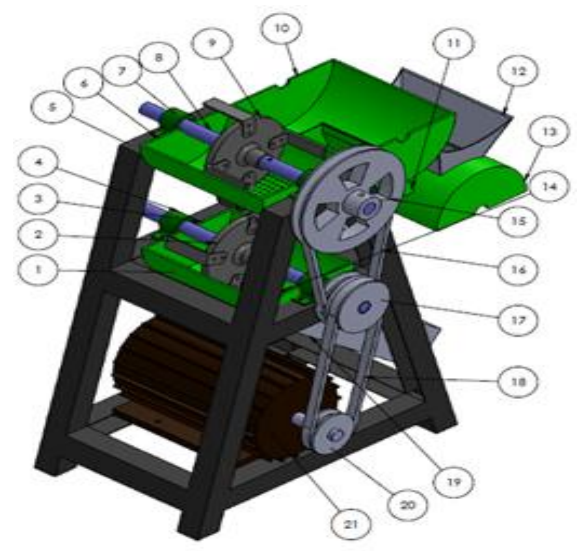

Gambar 2. Desain mesin perajang tembakau

2. Pelatihan penggunaan dan serah terima mesin perajang tembakau

Pada diseminasi yang dilakukan, kelompok tani diajarkan bagaimana cara kerja mesin dan mempraktikkan penggunaan mesin perajang tembakau dilakukan pelatihan pemotongan tembakau dengan mesin. Selain itu, mitra juga diajarkan cara perawatan mesin.

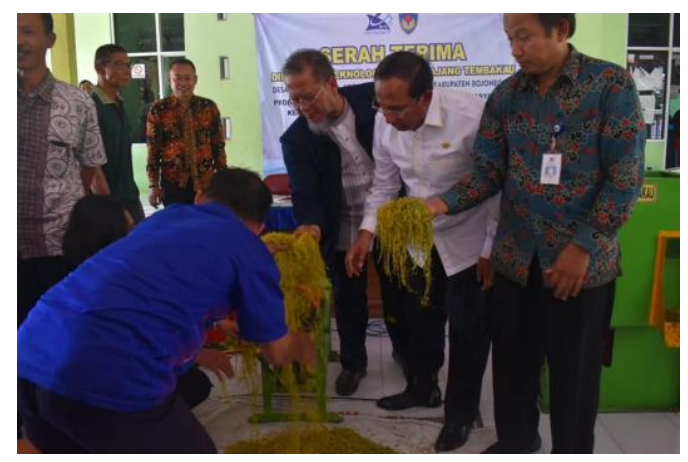

Gambar 3. Praktek penggunaan mesin perajang tembakau oleh warga 
3. Penyerahan mesin perajang kepada kelompok.

Setelah mitra memahami cara pengoperasionalan dan perawatan mesin perajang kemudian mesin perajang tembakau diserahkan kepada kelompok untuk digunakan sebagai alat produksi.

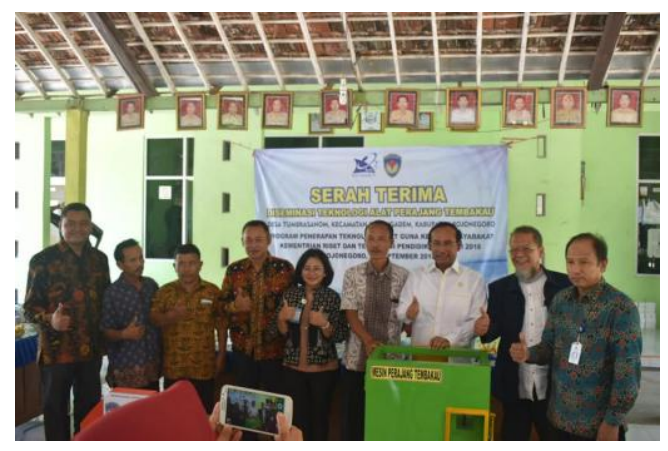

Gambar 4. Serah terima mesin perajang tembakau ke warga

4. Pelatihan manajemen finansial, penjualan dan pemasaran

Sebagai lanjutan dari penyerahan dan tindak lanjut dari pemetaan kebutuhan kelompok tani adalah pelatihan manajemen finansial, penjualan, dan pemasaran. Pelatihan ini dilakukan oleh tim IKIP PGRI Bojonegoro diketuai oleh Ali Mujahidin, MM.

\section{PEMBAHASAN}

\section{Pelatihan manajemen finansial,} penjualan dan pemasaran.

Melibatkan seluruh anggota kelompok.

Hasil pelatihan manajemen finansial menunjukkan bahwa seluruh peserta sebagian besar memahami apa yang disampaikan oleh penyaji, sehingga ada niatan dari para peserta untuk menerapkan hasil pelatihan tersebut. Dan ada peserta yang masih merasa kesulitan memahami dari apa yang disampaikan. Hal tersebut dikarenakan faktor usia dan latar belakang pendidikan. Terhadap warga desa Tumbrasanom yang faham materi manajemen finansial hasilnya mampu mengkalkulasi keuntungan dalam memproduksi dan menjual produk dengan berbagai varian mesin perajang tembakau. Pendekatan pelatihan berbasis pengelolaan yang sederhana (Bismala, 2017).

Berkaitan dengan pelatihan penjualan dan pemasaran, tim mengenalkan teknologi berupa sistem informasi dan media sosial berupa cara pembuatan web pemasaran via blog, twitter, facebook dan lain-lain sehingga warga mudah mencari konsumen secara cepat dan akurat. Hasil pelatihan pemasaran secara online yang dilakukan oleh tim kepada pembuat alat di desa Tumbrasanom Kecamatan Kedungadem Kabupaten Bojonegoro menunjukkan bahwa pembuatan web masih belum bisa dilakukan karena keterbatasan SDM. 
Pemasaran dan penyebaran informasi melalui sosial media berupa twitter, facebook, whatsapp, dan instagram sudah dilakukan karena pengoperasian lebih mudah. Respon dari masyarakat berkaitan promosi yang telah dilakukan oleh peserta pelatihan sangat menyambut baik, dimana ada peningkatan masyarakat yang menanyakan alat perajang tembakau yang telah diiklankan melalui sosial media baik itu twitter, facebook, whatsap, dan instagram.

Berkaitan dengan hal tersebut artinya masyarakat secara umum lebih mengenal suatu produk lebih banya melalui media sosial. Sehingga pentingnya literasi digital juga disampaikan dalam pelatihan (Gumilar, 2017).

Selain pelatihan yang telah dilakukan di atas tim juga melakukan pelatihan tentang studi kelayakan bisnis. Tteknik menganalisis kelayakan rencana bisnis sangat penting bagi pelaku usaha karena dapat digunakan dalam perencanaan dan pengembangan usaha ke depan (Abdisobar, Bakar, \& Yuniar, 2014). Oleh karena itu, masyarakat juga diajari cara dan teknik menganalisis kelayakan bisnis. Studi kelayakan sebelum suatu usaha sangat diperlukan agar usaha tersebut dijalankan tidak akan sia-sia atau membuang-buang uang, tenaga atau pikiran secara percuma serta tidak akan menimbulkan masalah yang tidak perlu dimasa yang akan datang. Studi kelayakan memiliki beberapa tujuan yaitu :

\section{Menghindari terjadinya resiko.} tujuan pertama dari studi kelayakan bisnis adalah menghindari terjadinya resiko yang dapat di kendalikan ataupun tidak bisa di kendalikan. Ketidakpastian kondisi masa depat membuat anda perlu mengadakan analisa studi kelayakan agar mengurangi terjadinya resiko

2. Mempermudah untuk membuat perencanaan. Dengan adanya prediksi masa depan usaha maka dapat mempermudah anda dalam merancang perencanaan bisnis. Didalam perencanaan tersebut dapat berupa modal, waktu pelaksanaan, tempat usaha, cara pelaksanaan, besarnya keuntungan serta pengawasan.

3. Mempermudah dalam pelaksanaan pekerjaan. Ketika perencanaan telah disusun dengan baik tentunya akan mempermudah kita dalam melaksanaan pekerjaan. Dengan demikian pekerjaan dapat dilakukan secara sistimatis dan setiap karyawan memiliki pedoman dan fokus pada tujuan.

\section{Mempermudah}

pengawasan.

Dengan adanya analisa studi kelayakan bisnis juga dapat 
mempermudah dalam pengawasan terhadap setiap proses bisnis yang dilaksanakan.

\section{Mempermudah pengendalian.}

Ketika terjadi penyimpangan dalam proses bisnis maka dengan adanya hasil studi kelayakan binis maka anda akan mudah untuk memperbaik dan langsung dapat di selesaikan.

Dari hasil pelatihan studi kelayakan bisnis sederhana dihasilkan pengusaha perakit alat perajang tembakau lebih dapat memantau dan mengendalikan proses perakitan alat perajang tembakau.

\section{Publikasi}

Publikasi kegiatan diseminasi perajang tembakau ini telah dipublikasi secara cetak dan online melalui TVRI Jawa Tengah. Hal ini dilakukan agar kegiatan diseminasi ini mampu meningkatkan promosi Desa Tumbrasanom dalam memanfaatkan mesin perajang tembakau kapan saja dan dimana saja.

\section{SIMPULAN DAN SARAN}

Simpulan kegiatan yang telah dilakukan dalam program Diseminasi Teknologi Mesin mesin perajang tembakau Bagi Masyarakat Desa Tumbrasanom Kecamatan kedungadem
Kabupaten Bojonegoro antara lain: masyarakat desa tumbrasanom sangat antusias dalam pelatihan cara penggunaan mesin perajang temabakau sehingga meningkatkan kenyamanan warga, tingkat antusiasme mengikuti pelatihan pembuatan mesin perajang tembakau, akan dilakukan pelatihan marketing penjualan mesin perajang tembakau pada bulan Oktober 2018, warga sangat terbantu dengan adanya varian mesin perajang tembakau tenaga listrik dan diesel sehingga bisa merajang tembakau di rumah dan di sawah.

Secara umum produk mesin perajang tembakau sangat diminati warga desa tumbrasanom karena mampu menjadi solusi atas terjadinya penumpukan panen tembakau yang akhirnya laku terjual dengan baik, adapun yang perlu diperbaiki adalah: peserta pelatihan perlu ditambah lagi, sehingga tidak hanya 10 warga perwakilan RT dan RW saja, pelatihan perakitan produk mesin perajang tembakau perlu dilakukan secara berulang, sehingga warga lebih mudah menggunakannya, perlu diajak karang taruna sebagai wakil generasi muda dalam membangun Desa Tumbrasanom, ger box perlu dibuat lebih rendah, sehingga tidak mengenai tembakau yang akhirnya jadi merusak daun tembakau. 


\section{UCAPAN TERIMA KASIH}

Ucapan Terima kasih kami sampaikan pada Kemenristekdikti yang telah memberikan pendanaan sehingga Diseminasi mesin perajang tembakau ini terlaksana. Kepala Desa Tumbrasanom yang telah bersedia menerima tim pengabdi. Kepala Kelompok Tani Makmur 1 dan Kelompok Tani Makmur 3 yang dengan terbuka dan antusias mengikuti kegiatan. Universitas PGRI Semarang dan IKIP PGRI Bojonegoro yang telah membantu terlaksananya kegiatan diseminasi ini.

\section{DAFTAR PUSTAKA}

Perkebunan, D. J. (2016). Statistik Perkebunan Indonesia 20152017. Jakarta: Direktorat Jendral Perkebunan Kementerian Pertanian. Abdisobar, R., Bakar, A., \& Yuniar, Y. (2014). Analisis Kelayakan Usaha Budidaya Jamur Tiram di Desa Cilame Ciwidey Kabupaten Bandung. Reka Integra, 2(1). Diambil dari https://ejurnal.itenas.ac.id/index.php/ rekaintegra/article/view/391

Amelia, K., Iqbal, I., \& Useng, D. (2018). Uji Kinerja Alat Perajang Rimpang Jurnal Agritechno dari http://agritech.unhas.ac.id/ojs/index. php/at/article/view/43
Bismala, L. (2017). Model Manajemen Usaha Mikro Kecil dan Menengah (UMKM) untuk Meningkatkan Efektivitas Usaha Kecil Menengah. Jurnal Entrepreneur dan Entrepreneurship, 5(1), 19-26.

Gumilar, G. (2017). Literasi media: Cerdas menggunakan media sosial dalam menanggulangi berita palsu (HOAX) Oleh Siswa SMA. Jurnal Pengabdian Kepada Masyarakat, l(1).

Nur, Y. H., \& Salim, Z. (2018). Daya Saing Tembakau Virginia Lokal: Analisis Rantai Nilai. Jurnal Ekonomi dan Pembangunan, 22(1), $1-10$. https://doi.org/10.14203/JEP.22.1.20 14.15-24

Sugandi, W. K., Yusuf, A., \& Saukat, M. (2016). Rancang Bangun Dan Uji Kinerja Mesin Pencacah Rumput Gajah Untuk Pakan Ternak Dengan Menggunakan Pisau Tipe Reel (Construction Design and Test Performance of Elephant Grass for Cattle Feed using Reel Type Knife). Jurnal Ilmiah Rekayasa Pertanian dan Biosistem, 4(1), 200-206. Diambil dari http://jrpb.unram.ac.id/index.php/jrp b/article/view/20 